\title{
Strategies for successful implementation and permanent maintenance of a rapid response system
}

Myung Jin Song and Yeon Joo Lee

\author{
Division of Pulmonary and Critical \\ Care Medicine, Department of \\ Internal Medicine, Seoul National \\ University Bundang Hospital, \\ Seongnam, Korea \\ Received: December 29, 2020 \\ Accepted: March 17, 2021

\section{Correspondence to} \\ Yeon Joo Lee, M.D. \\ Division of Pulmonary and \\ Critical Care Medicine, Depart- \\ ment of Internal Medicine, Seoul \\ National University Bundang \\ Hospital, 82 Gumi-ro 173beon- \\ gil, Bundang-gu, Seongnam \\ 13620 , Korea \\ Tel: +82-31-787-7082 \\ Fax: +82.31-787-4051 \\ E-mail: yeonjoolee1117@gmail.com \\ https://orcid.org/0000-0001- \\ 7697-4272
}

Rapid response systems (RRSs) have been introduced to intervene with patients experiencing non-code medical emergencies and operate widely around the world. An RRS has four components: an afferent limb, an efferent limb, quality improvement, and administration. A proper triggering system, a hospital culture that embraces the RRS from the afferent limb, experienced primary responders, and dedicated physicians from the efferent limb are key for successful implementation. After initial implementation, quality improvement through objective outcome measures and self-evaluation are crucial, which lead to a better outcome when this process is well performed. Furthermore, better outcomes lead to more investment, which is essential for effective development of the system. The RRS is successfully maintained when these four components are closely interconnected.

Keywords: Hospital rapid response team; Maintenance; Quality improvement

\section{INTRODUCTION}

Rapid response systems (RRSs) have been introduced to intervene in patients experiencing non-code medical emergencies. An RRS involves monitoring deterioration in patients and alarms linked to a team of responders who provide critical care resources at the patient's location [1].

Previous studies have reported that $60 \%$ of in-hospital cardiac arrests had at least one vital sign abnormality before the cardiac arrest [2], suggesting that such antecedents may rescue the patient from irreversible mortality if recognized and treated appropriately. This concept of "rescue" is the rationale for developing an RRS.

After the 100,000 Lives Campaign launched by the Institute for Healthcare Improvement in 2004 proposed "deployment of a RRS" as the first intervention to save patients' lives in hospitals through improvements in the safety of health care [3], hospitals in the United States and Australia started to deploy RRSs widely. RRSs began in Korea in 2008.

As many hospitals from different countries employ RRSs, several studies have evaluated the effectiveness of RRSs. However, the results are controversial and evidence supporting RRSs remains unclear. Many observational studies have shown a reduction in cardiopulmonary arrest in the general ward after implementing an RRS [4-8], but the only multicenter randomized study, the Medical Early Response Intervention and Therapy (MERIT) trial, did not demonstrate the benefit of an RRS [9]. This controversy was likely to have been caused by variety in the composition and operating systems of 


\section{KJIM'}

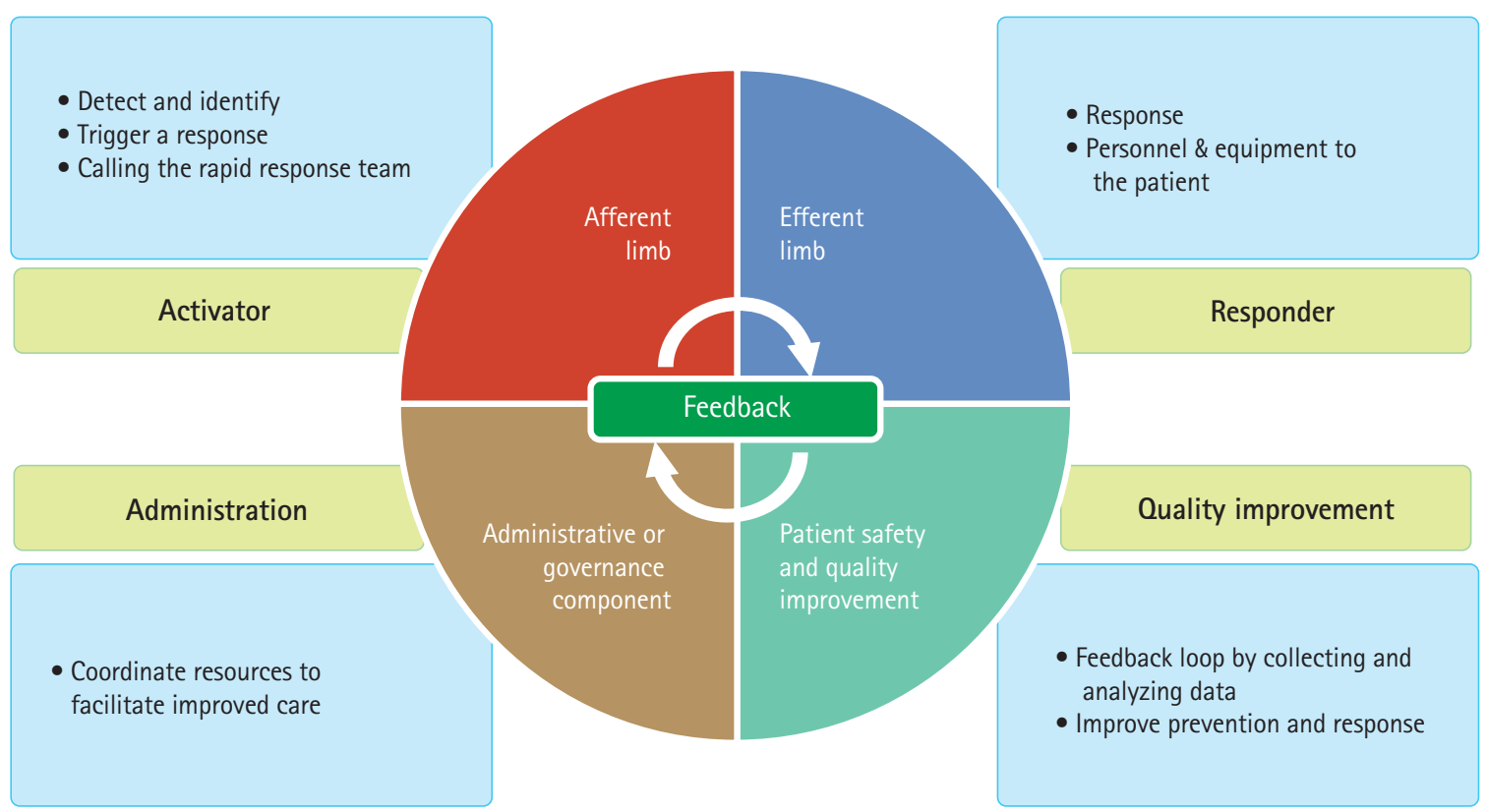

Figure 1. The four components of a rapid response system.

the rapid response teams (RRT). At the same time, the controversy also suggests that it is not enough just to start an RRS; it is also necessary to determine how to configure and operate the RRT for it to be effective. An RRS is a coherent and integrated system of care with four basic components: an afferent limb, an efferent limb, quality improvement, and administration (Fig. 1) [10]. In this review, we proposed strategies to implement and successfully maintain RRSs using these four components.

\section{KEY STRATEGIES IN THE AFFERENT LIMB: AN EFFECTIVE TRIGGERING SYSTEM AND A HOS- PITAL CULTURE THAT EMBRACES THE RRS}

The afferent limb is designed to identify clinical deterioration in patients and trigger a response. This component includes the criteria for calling the RRT, the means to assess the calls, the personnel who trigger activation of the RRS, and the mechanism of activation [1].

The calling criteria that trigger the RRS are based on the patients' vital signs and laboratory values. A single
Table 1. Activation criteria for rapid response team of Seoul National University Bundang Hospital (single parameter early warning system)

\begin{tabular}{|c|c|}
\hline Variable & Activation criteria \\
\hline Systolic blood pressure, $\mathrm{mmHg}$ & $<90$ \\
\hline Heart rate, /min & $<50$ or $>140$ \\
\hline Respiratory rate, /min & $<10$ or $>30$ \\
\hline Body temperature, ${ }^{\circ} \mathrm{C}$ & $>39$ or $<36$ \\
\hline Oxygen saturation, \% & $<90$ \\
\hline $\mathrm{pH}$ & $<7.25$ \\
\hline $\mathrm{PaCO}_{2}, \mathrm{mmHg}$ & $>50$ \\
\hline $\mathrm{PO}_{2}, \mathrm{mmHg}$ & $<55$ \\
\hline Lactic acid, mmol/L & $>4$ \\
\hline Total $\mathrm{CO}_{2}, \mathrm{mmol} / \mathrm{L}$ & $<15$ \\
\hline
\end{tabular}

Any serious concern about overall deterioration detected by doctor, nurse, and caregiver at bedside.

parameter early warning system (EWS) and a multi-parameter EWS are the two representative types of triggering systems used in RRSs. Single parameter triggering is a set of equally weighted abnormal physiological param- 
eters that are used predominantly in American centers and most Australian centers [10]. These single-parameter criteria are formed based on expert's knowledge of physiological data related to adverse clinical outcomes. There are slight differences in the thresholds of the parameters between hospitals, but the big picture is similar. Our hospital uses a single parameter EWS, and the triggering set is shown in Table 1. A multi-parameter EWS sums up multiple parameters of derangement. The United Kingdom has widely adopted multi-parameter EWS and representative scoring systems are the Modified Early Warning System (MEWS) and the National Early Warning Score (Table 2) [11,12]. A multi-parameter EWS can detect subtle abnormalities in multiple vital signs that can be missed by a single parameter EWS, which detects extreme deterioration in a single parameter [13]. However, a single parameter scoring system has the advantage of being able to evaluate the patient's condition intuitively as the system is composed of parameters used in clinical practice and has been reported not to be inferior to multi-parameter EWS [14].

Traditional EWSs have common limitations of low sensitivity and a high false alarm rate $[15,16]$. Increased mortality occurs when RRS triggering is delayed due to the low sensitivity of the triggering criteria [17]. However, if an alarm goes off on too many patients, the staff will become desensitized to the false alarms [18]. To improve this limitation, several studies have developed algorithms based on artificial intelligence to achieve both high sensitivity and specificity when triggering the RRS [19-21]. Machine-learning-based EWSs are more effective at detecting clinical deterioration of patients than traditional EWSs, but they have limited ability to process raw data and require a careful developmental phase that can lead to information loss [19]. Deep-learning-based EWSs include feature learning, a method in which a model is fed raw data to identify automatically the features needed to conduct a task [22]. In South Korea, deep-learning-based EWS was developed using four basic vital signs, including systolic blood pressure, heart rate, respiratory rate, and body temperature. These EWS criteria have led to higher sensitivity with fewer alarms than a traditional triggering system, such as the MEWS with single triggering criteria [20,21]. However, evidence for the clinical use of these new EWSs is limited and they must be validated in multiple centers. Addition-

Table 2. Two representative multi-parameter early warning system

\begin{tabular}{|c|c|c|c|c|c|c|c|}
\hline & 3 & 2 & 1 & o & 1 & 2 & 3 \\
\hline \multicolumn{8}{|l|}{$\begin{array}{l}\text { (a) Modified Early Warning } \\
\text { System (MEWS) }\end{array}$} \\
\hline Respiratory rate per minute & & $<9$ & & $9-14$ & $15-20$ & $21-29$ & $\geq 30$ \\
\hline Heart rate per minute & & $<40$ & $41-50$ & $51-100$ & $101-110$ & $111-129$ & $\geq 130$ \\
\hline Systolic blood pressure, $\mathrm{mmHg}$ & $<70$ & $71-80$ & $81-100$ & $101-199$ & & $\geq 200$ & \\
\hline Level of consciousness & & & & Alert & $\begin{array}{l}\text { Reacting to } \\
\text { Voice }\end{array}$ & $\begin{array}{l}\text { Reacting to } \\
\text { Pain }\end{array}$ & Unresponsive \\
\hline Temperature, ${ }^{\circ} \mathrm{C}$ & & $<35$ & & $35-38.4$ & & $\geq 38.5$ & \\
\hline \multicolumn{8}{|l|}{$\begin{array}{l}\text { (b) National Early Warning } \\
\text { Score (NEWS) }\end{array}$} \\
\hline Respiratory rate per minute & $\leq 8$ & & $9-11$ & $12-20$ & & $21-24$ & $\geq 25$ \\
\hline Heart rate per minute & $\leq 40$ & & $41-50$ & $51-90$ & $91-110$ & $111-130$ & $\geq 131$ \\
\hline Systolic blood pressure, $\mathrm{mmHg}$ & $\leq 90$ & $91-100$ & $101-110$ & $111-129$ & & & $\geq 220$ \\
\hline Oxygen saturation, \% & $\leq 91$ & $92-93$ & $94-95$ & $\geq 96$ & & & \\
\hline Any supplemental oxygen & & Yes & & No & & & \\
\hline Level of consciousness & & & & A & & & $\mathrm{V}, \mathrm{P}$ or $\mathrm{U}$ \\
\hline Temperature, ${ }^{\circ} \mathrm{C}$ & $\leq 35.0$ & & $35.1-36.0$ & $36.1-38.0$ & $38.1-39.0$ & $\geq 39.1$ & \\
\hline
\end{tabular}

A, alert; V, voice; P, pain; U, unconscious. 
ally, safety and effectiveness should be demonstrated through well-designed prospective clinical trials.

In addition to the objective criteria of the EWS, anyone who detects a patient's acute deterioration can activate the RRS through a call. Usually, the hospital ward team (nurse, resident, technician, and staff) triggers the RRS directly through a call. Moreover, it is recommended that the RRS be activated by patients or family members when they are concerned about patient status [23]. This recommendation has been proposed to protect patients when healthcare workers do not recognize patient deterioration, particularly in pediatric or older patients who cannot seek help on their own when they feel their condition is worsening. Several studies have reported the impact of patient and family escalation of care, and patient and family feedback was uniformly positive. However, there appeared to be a level of staff stress associated with unnecessary calls, particularly related to unresolved communication issues with healthcare staff that were unrelated to suspected clinical deterioration [24-26]. Only a few hospitals ( $2 \%$ of the hospitals in the northeastern United States from a recent report) have adopted patient and family-member-led escalation approaches [27], as they require protocols tailored to the hospital situation and education of patients and family members [28].

Hospital culture can be another important factor in activation of the RRS. The ward team may be resistant to the RRT being involved in treatment, and the ward team may find it difficult to ask the RRT for help. The hospital culture in which an RRS is implemented with the support of nurses and doctors in the hospital is important. Patient and family feedback was uniformly positive. There appeared to be a level of staff stress associated with introducing a new process that goes beyond the traditional hierarchical system.

\section{KEY STRATEGIES FOR THE EFFERENT LIMB: QUALIFIED PRIMARY RESPONDERS AND DED- ICATED PHYSICIANS}

The efferent limb is the response arm and includes the personnel and equipment brought to the patient. Mature academic systems have at least 25 to 55 calls per 1,000 admissions [29]. An increase in RRT dose has been reported to be associated with a progressive reduction in the incidence of cardiac arrest $[4,5]$.

The efferent limb of an RRS is usually a multidisciplinary team composed of a critical care registered nurse, respiratory therapist, and physicians. Composition varies widely between hospitals according to the availability of resources and medical staff at each center [27]. The effectiveness of an RRS is intrinsically linked to its composition, as providers' ability to triage and stabilize deteriorating patients depends on the providers' expertise. However, the most effective team configuration remains uncertain [30]. We plan to investigate the composition of the RRT in terms of the primary responder and the team leader.

Once an RRS is triggered, the primary responder checks the alarm and performs an initial assessment. Most primary responders in an RRS are registered nurses and are part of the RRT, while the primary responder is usually a physician on the medical emergency team. As described above for the afferent limb, a conventional RRS triggering system has several limitations in terms of sensitivity and specificity. Therefore, the primary responder needs to determine whether the alarm is clinically important and requires immediate escalation to a higher level of management, or a false alarm. In our hospital, we studied the effectiveness of subjective assessment (patient acuity rating scale) of the triggered patient by experienced RRT nurses and confirmed that the subjective assessment scale of RRT nurses was superior to single parameter triggering or multi-parameter EWS in predicting the patient's short term prognosis [31,32]. This result shows that an experienced and well-trained primary responder is crucial to an RRT.

Most RRTs are led by an attending physician (intensivist or non-intensivist) or a trainee physician [27]. No benefit on in-hospital mortality has been reported when an intensivist leads the RRT compared to a trainee physician [33,34]. According to a recently published study, top-performing hospitals have dedicated team leaders without other clinical responsibilities, whereas leaders of RRTs at bottom-performing hospitals have other competing clinical responsibilities [35]. Based on these reports and our experience, the presence of a dedicated physician leader, whether it is an intensivist or a trainee physician, is more important than who is the leading physician. 


\section{KEY STRATEGIES FOR IMPROVING QUALITY: REGULAR EVALUATION OF OUTCOMES AND FEEDBACK OF TEAM ACTIVITY}

The afferent and efferent limbs are important elements in the initial implementation of an RRS, whereas quality improvement is the key element to successfully maintaining the RRS. Regular evaluations of the function and effectiveness of the team using proper objective metrics are mandatory to guide subsequent quality improvement activities. Self-evaluation within the team is essential, and evaluation from outside the team is also helpful. As a target outcome, ten quality metrics to evaluate an RRS have been proposed by the Third International Consensus Conference on rapid response systems (Table 3) [23]. Several parameters are difficult to apply to Korean RRSs. However, the following four metrics must be monitored regularly by the team: (1) cardiac arrests in general ward patients; (2) predictable cardiac arrests in general ward patients; (3) timeliness of the response to ward-patient deterioration; and (4) timeliness of critical care interventions. In addition, it is important to review each case that activated the RRT to determine whether there was a failure and, if so, the cause of the failure should be discussed by the team and feedback should be provided through weekly or biweekly meetings. Quality improvement occurs when RRTs review their activities by evaluating the outcomes and actively monitor medical errors as well as educational opportunities for RRT members $[36,37]$. Using this process, the team can successfully establish itself in the hospital while finding the optimal direction for activities.

In our hospital, objective metrics are regularly monitored and RRT meetings are held every 2 weeks to review all cases transferred from the general ward to the intensive care unit (ICU), and those in which cardiac arrest occurred in the general ward. As results, the incidence of cardiac arrests in the general ward decreased by $4 \%$ annually (incidence rate ratio, 0.96; 95\% confidential interval, 0.94 to $0.89 ; p<0.001$ ) (Fig. 2).

\section{KEY STRATEGY FOR ADMINISTRATION: PROP- ER FUNDING SUPPORT}

Funding support is required to implement the afferent and efferent limbs and operate an RRT. The administrative component coordinates funding resources to facilitate improved care, oversees the appointment of the response-team staff and the purchase of equipment, and coordinates education of the hospital staff regarding the rapid-response process [10].

Since RRSs have been implemented in Korea, many hospitals have known that an RRS helps improve patient safety but that implementation of an RRS is difficult because of the lack of national support from an insurance fee. Most RRS-operating hospitals in Korea do not hire an extra dedicated physician for the RRS. Instead, existing staff members, usually intensivists, spontaneously participate in the RRT for patient safety.

A huge change in the national support for RRSs occurred in May 2019. The Korean Health Insurance Review \& Assessment Service and Ministry of Health and Welfare started an RRS pilot program to expand RRSs [38]. The Ministry of Health and Welfare began to support the health insurance fee per day to inpatients for RRS-operating hospitals with more than 300 beds. The degree of support was divided into three levels, according to the operating hours and manpower (Table 4). To receive the group 1 insurance fee, the RRS must operate 24 hours per day 365 days per year, and the RRT must include at least one dedicated physician and nine dedicated nurses. A video laryngoscope, portable ventilator, portable ultrasound, and a point-of-care test machine should be equipped to receive group 1 support. Although the start of the pilot program is encouraging, there is still much room for improvement in the program. First, a dedicated RRS physician is mandatory only in group 1 of the current pilot program. As nurses do not have the authority to order, it is bound to be a limited role, particularly if a major decision about a patient's condition and management is needed. The burden on the intensivist increases in most group 2 and 3 hospitals of the pilot program because the intensivist is working in dual roles (ICU and RRS) without an RRS-dedicated physician. Therefore, the current pilot program needs to be revised so dedicated doctors must be deployed in groups 2 and 3. Second, the scale of support remains insufficient to operate and maintain an RRS. However, a lack of funding support is not only a Korean problem. In Australia and New Zealand, where RRSs are relatively well supported, only $13.7 \%$ are fully funded and $15.7 \%$ 
Table 3. Ten quality metrics for the evaluation of rapid response systems [23]

\begin{tabular}{|c|c|c|c|c|c|}
\hline Metric & Description & Level & Type & Numerator & Denominator \\
\hline 1 & $\begin{array}{l}\text { Cardiac arrests in } \\
\text { general ward patients }\end{array}$ & Essential & $\begin{array}{l}\text { Clinical } \\
\text { outcome }\end{array}$ & Non-ICU, non-procedural IHCA & $\begin{array}{l}\text { 10,000 Adult ward bed } \\
\text { days, including DNAR } \\
\text { patients }\end{array}$ \\
\hline 2 & $\begin{array}{l}\text { Predictable cardiac } \\
\text { arrests in general ward } \\
\text { patients }\end{array}$ & Essential & $\begin{array}{l}\text { Clinical } \\
\text { outcome }\end{array}$ & $\begin{array}{l}\text { Cardiac arrests occurring in } \\
\text { hospitalized ward patients who met } \\
\text { the hospital's escalation threshold at } \\
\text { least } 30 \text { minutes prior to and within } \\
24 \text { hours of the cardiac arrest }\end{array}$ & $\begin{array}{l}\text { 10,000 Adult ward bed } \\
\text { days, including DNAR } \\
\text { patients }\end{array}$ \\
\hline 3 & $\begin{array}{l}\text { Timeliness of their } \\
\text { response to ward } \\
\text { patient deterioration }\end{array}$ & Recommended & $\begin{array}{l}\text { Process } \\
\text { measure }\end{array}$ & $\begin{array}{l}\text { Hospitalized ward patients evaluated } \\
\text { by critical care personnel within the } \\
\text { time frame specified by the hospital } \\
\text { for such evaluation }\end{array}$ & $\begin{array}{l}\text { All ward patients } \\
\text { meeting deterioration } \\
\text { criteria that would } \\
\text { lead to the summons } \\
\text { or consultation by } \\
\text { ICU personnel }\end{array}$ \\
\hline 4 & $\begin{array}{l}\text { Timeliness of critical } \\
\text { care interventions }\end{array}$ & Recommended & $\begin{array}{l}\text { Process } \\
\text { measure }\end{array}$ & $\begin{array}{l}\text { Patients receiving critical care } \\
\text { application within } 6 \text { hours } \\
\text { following first threshold breach }\end{array}$ & $\begin{array}{l}\text { Patients receiving } \\
\text { critical care services } \\
\text { who breached } \\
\text { threshold in prior } 24 \\
\text { hours }\end{array}$ \\
\hline 5 & $\begin{array}{l}\text { Patients that exhibit } \\
\text { warning signs should } \\
\text { receive a timely } \\
\text { documentation of } \\
\text { goals of care }\end{array}$ & Optional & $\begin{array}{l}\text { Process } \\
\text { measure }\end{array}$ & $\begin{array}{l}\text { The proportion of hospitalized } \\
\text { ward patients in whom there was } \\
\text { an escalation criteria breach who } \\
\text { had goals of care discussions either } \\
\text { in place, or newly documented } \\
\text { by a clinical provider within } 24 \\
\text { hours of first breaching the clinical } \\
\text { escalation criteria }\end{array}$ & $\begin{array}{l}\text { All hospitalized ward } \\
\text { patients breaching } \\
\text { escalation criteria. }\end{array}$ \\
\hline 6 & $\begin{array}{l}\text { Means by which } \\
\text { patients and family } \\
\text { members can activate } \\
\text { the RRT }\end{array}$ & Essential & $\begin{array}{l}\text { Structural } \\
\text { metric }\end{array}$ & $\begin{array}{l}\text { Hospitals offering means for self or } \\
\text { caregiver activation of RRT }\end{array}$ & NA \\
\hline 7 & $\begin{array}{l}\text { Frequency of RRT } \\
\text { activations generated } \\
\text { by patients and family } \\
\text { members }\end{array}$ & Optional & $\begin{array}{l}\text { Process } \\
\text { measure }\end{array}$ & $\begin{array}{l}\text { The number of patient or family } \\
\text { activated RRT calls }\end{array}$ & $\begin{array}{l}\text { Total number of } \\
\text { RRT activations for } \\
\text { inpatients }\end{array}$ \\
\hline 8 & $\begin{array}{l}\text { Safety culture in } \\
\text { relation to detection } \\
\text { and response to } \\
\text { deteriorating patients }\end{array}$ & Recommended & $\begin{array}{l}\text { Structural } \\
\text { metric }\end{array}$ & $\begin{array}{l}\text { Hospitals conducting evaluations of } \\
\text { safety culture }\end{array}$ & NA \\
\hline 9 & $\begin{array}{l}\text { Length of stay on } \\
\text { general wards of all } \\
\text { patients with a breach } \\
\text { of escalation criteria } \\
\text { (including ICU cost) }\end{array}$ & Exploratory & $\begin{array}{l}\text { Cost } \\
\text { measure }\end{array}$ & $\begin{array}{l}\text { The total length of stay for ward } \\
\text { patients who breach escalation } \\
\text { criteria. Patients with timely } \\
\text { documented goals of care (metric 5) } \\
\text { should be differentiated from those } \\
\text { lacking such care plans. }\end{array}$ & NA \\
\hline 10 & $\begin{array}{l}\text { ICU length of stay of } \\
\text { patients transferred to } \\
\text { ICU following breach } \\
\text { of local escalation } \\
\text { criteria }\end{array}$ & Exploratory & $\begin{array}{l}\text { Cost } \\
\text { measure }\end{array}$ & $\begin{array}{l}\text { Duration of ICU stay in days for all } \\
\text { hospitalized ward patients meeting } \\
\text { escalation criteria in the } 24 \text { hours } \\
\text { prior to ICU transfer with delay and } \\
\text { without delay }\end{array}$ & NA \\
\hline
\end{tabular}

ICU, intensive care unit; IHCA, in-hospital cardiac arrest; DNAR, do-not-attempt-resuscitation; RRT, rapid response team; NA, not applicable. 


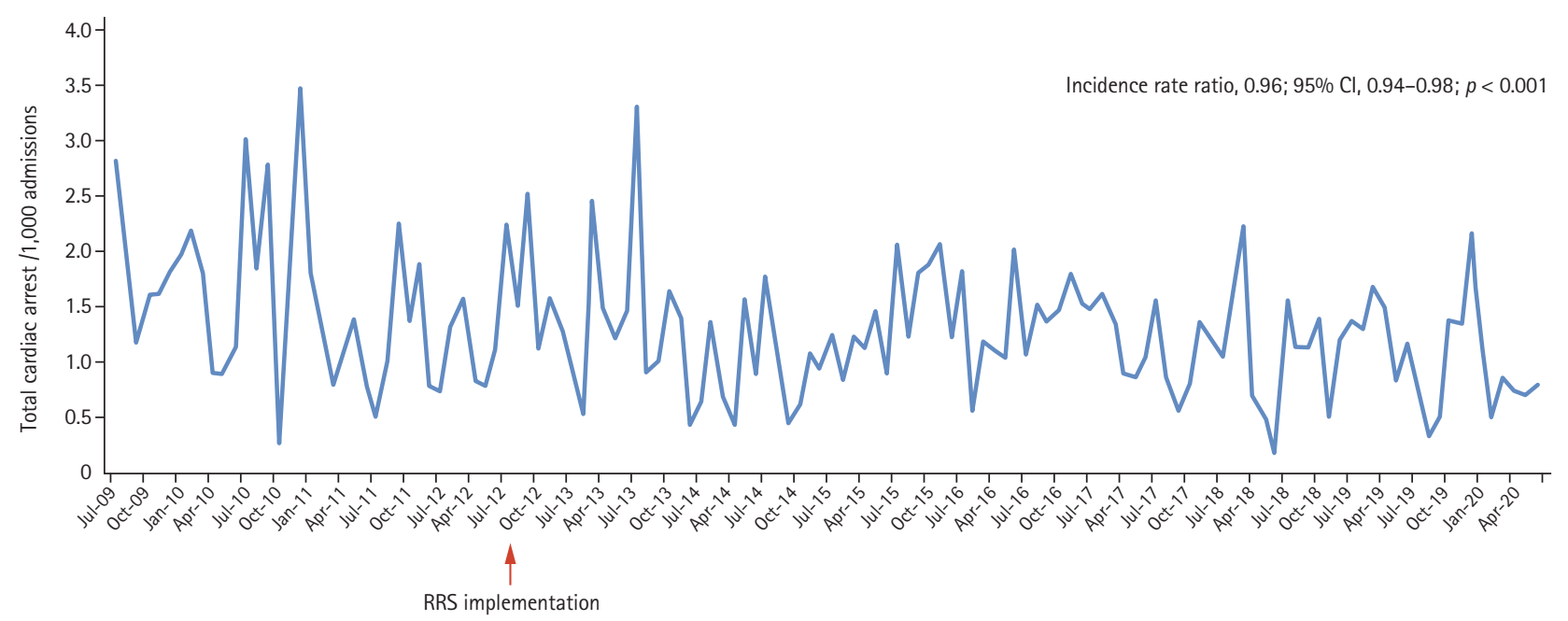

Figure 2. The incidence of total cardiac arrests in the general ward (total cardiac arrests/1,00o admissions). CI, confidence interval; RRS, rapid response system.

Table 4. National support by rapid response system pilot program in Korea since May 2019

\begin{tabular}{|c|c|c|c|c|c|}
\hline \multirow{2}{*}{ Level } & \multirow{2}{*}{ Operation hours } & \multirow{2}{*}{$\begin{array}{l}\text { Management fee } \\
\text { (Korean won per one inpatient, a day) }\end{array}$} & \multicolumn{2}{|c|}{ Dedicated manpower } & \multirow{2}{*}{ Equipment $^{\mathrm{a}}$} \\
\hline & & & Doctor & Nurse & \\
\hline 1 & 7 days/week, 24 hours & 1,260 & 1 & 9 & 4 \\
\hline 2 & 5 days/week, 16 hours & 610 & - & 5 & 4 \\
\hline 3 & 5 days/week, 8 hours & 310 & - & 2 & 2 \\
\hline
\end{tabular}

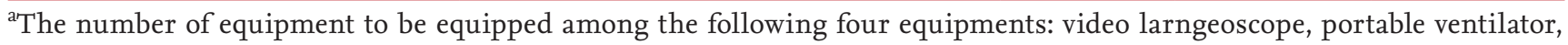
portable ultrasound, point of care test machine.

are partially funded. Thus, two-thirds do not receive any support [39]. More active interest and investment by the government and hospital management are required in RRSs.

\section{CONCLUSIONS}

In this article, we have reviewed the strategies to implement and maintain successfully an RRS according to four components. A proper triggering system, a hospital culture that embraces the RRS, experienced primary responders, and a dedicated physician are key strategies for successful implementation. After the initial implementation, quality improvement through periodic self-evaluation is necessary to achieve better outcomes, and better outcomes lead to more investment in the system. Investment in the system will lead to more effec- tive development of the system. These four components should be closely interconnected for an RRS to be maintained successfully, leading eventually to a permanent system.

\section{Conflict of interest}

No potential conflict of interest relevant to this article was reported.

\section{REFERENCES}

1. Bedell SE, Deitz DC, Leeman D, Delbanco TL. Incidence and characteristics of preventable iatrogenic cardiac arrests. JAMA 1991;265:2815-2820.

2. Andersen LW, Kim WY, Chase M, et al. The prevalence and significance of abnormal vital signs prior to in-hospital cardiac arrest. Resuscitation 2016;98:112-117. 
3. Berwick DM, Calkins DR, McCannon CJ, Hackbarth AD. The 100,000 lives campaign: setting a goal and a deadline for improving health care quality. JAMA 2006;295:324-7.

4. DeVita MA, Braithwaite RS, Mahidhara R, et al. Use of medical emergency team responses to reduce hospital cardiopulmonary arrests. Qual Saf Health Care 2004;13:251-254.

5. Buist M, Harrison J, Abaloz E, Van Dyke S. Six year audit of cardiac arrests and medical emergency team calls in an Australian outer metropolitan teaching hospital. BMJ 2007;335:1210-1212.

6. Dacey MJ, Mirza ER, Wilcox V, et al. The effect of a rapid response team on major clinical outcome measures in a community hospital. Crit Care Med 2007;35:2076-2082.

7. Offner PJ, Heit J, Roberts R. Implementation of a rapid response team decreases cardiac arrest outside of the intensive care unit. J Trauma 2007;62:1223-1228.

8. Sharek PJ, Parast LM, Leong K, et al. Effect of a rapid response team on hospital-wide mortality and code rates outside the ICU in a children's hospital. JAMA 2007;298:2267-2274.

9. Hillman K, Chen J, Cretikos M, et al. Introduction of the medical emergency team (MET) system: a cluster-randomised controlled trial. Lancet 2005;365:2091-2097.

10. Jones DA, DeVita MA, Bellomo R. Rapid-response teams. N Engl J Med 2011;365:139-146.

11. Subbe CP, Kruger M, Rutherford P, Gemmel L. Validation of a modified Early Warning Score in medical admissions. QJM 2001;94:521-526.

12. Smith GB, Prytherch DR, Jarvis S, et al. A comparison of the ability of the physiologic components of medical emergency team criteria and the U.K. National Early Warning Score to discriminate patients at risk of a range of adverse clinical outcomes. Crit Care Med 2016;44:21712181.

13. Jarvis S, Kovacs C, Briggs J, et al. Aggregate National Early Warning Score (NEWS) values are more important than high scores for a single vital signs parameter for discriminating the risk of adverse outcomes. Resuscitation 2015;87:75-80.

14. Romero-Brufau S, Huddleston JM, Naessens JM, et al. Widely used track and trigger scores: are they ready for automation in practice? Resuscitation 2014;85:549-552.

15. Smith GB, Prytherch DR, Schmidt PE, Featherstone PI. Review and performance evaluation of aggregate weighted 'track and trigger' systems. Resuscitation 2008;77:170-
179.

16. Smith GB, Prytherch DR, Schmidt PE, Featherstone PI, Higgins B. A review, and performance evaluation, of single-parameter "track and trigger" systems. Resuscitation 2008;79:11-21.

17. Boniatti MM, Azzolini N, Viana MV, et al. Delayed medical emergency team calls and associated outcomes. Crit Care Med 2014;42:26-30.

18. Shearer B, Marshall S, Buist MD, et al. What stops hospital clinical staff from following protocols?: an analysis of the incidence and factors behind the failure of bedside clinical staff to activate the rapid response system in a multi-campus Australian metropolitan healthcare service. BMJ Qual Saf 2012;21:569-575.

19. Churpek MM, Yuen TC, Winslow C, Meltzer DO, Kattan MW, Edelson DP. Multicenter comparison of machine learning methods and conventional regression for predicting clinical deterioration on the wards. Crit Care Med 2016;44:368-374.

20. Kwon JM, Lee Y, Lee Y, Lee S, Park J. An algorithm based on deep learning for predicting in-hospital cardiac arrest. J Am Heart Assoc 2018;7:eoo8678.

21. Cho KJ, Kwon O, Kwon JM, et al. Detecting patient deterioration using artificial intelligence in a rapid response system. Crit Care Med 2020;48:e285-e289.

22. LeCun Y, Bengio Y, Hinton G. Deep learning. Nature 2015;521:436-444.

23. Subbe CP, Bannard-Smith J, Bunch J, et al. Quality metrics for the evaluation of rapid response systems: proceedings from the third international consensus conference on Rapid Response Systems. Resuscitation 2019;141:1-12.

24. Gill FJ, Leslie GD, Marshall AP. The impact of implementation of family-initiated escalation of care for the deteriorating patient in hospital: a systematic review. Worldviews Evid Based Nurs 2016;13:303-313.

25. Vorwerk J, King L. Consumer participation in early detection of the deteriorating patient and call activation to rapid response systems: a literature review. J Clin Nurs 2016;25:38-52.

26. Albutt AK, O'Hara JK, Conner MT, Fletcher SJ, Lawton RJ. Is there a role for patients and their relatives in escalating clinical deterioration in hospital?: a systematic review. Health Expect 2017;20:818-825.

27. Mitchell OJL, Motschwiller CW, Horowitz JM, Evans LE, Mukherjee V. Characterising variation in composition 
and activation criteria of rapid response and cardiac arrest teams: a survey of Medicare participating hospitals in five American states. BMJ Open 2019;9:e024548.

28. See MT, Chan WC, Huggan PJ, Tay YK, Liaw SY. Effectiveness of a patient education intervention in enhancing the self-efficacy of hospitalized patients to recognize and report acute deteriorating conditions. Patient Educ Couns 2014;97:122-127.

29. Jones D, Bellomo R, DeVita MA. Effectiveness of the medical emergency team: the importance of dose. Crit Care 2009;13:313.

30. Olsen SL, Soreide E, Hillman K, Hansen BS. Succeeding with rapid response systems: a never-ending process: a systematic review of how health-care professionals perceive facilitators and barriers within the limbs of the RRS. Resuscitation 2019;144:75-90.

31. Kim HJ, Min HJ, Lee DS, et al. Performance of patient acuity rating by rapid response team nurses for predicting short-term prognosis. PLoS One 2019;14:e0225229.

32. Edelson DP, Retzer E, Weidman EK, et al. Patient acuity rating: quantifying clinical judgment regarding inpatient stability. J Hosp Med 2011;6:475-479.

33. Karvellas CJ, de Souza IA, Gibney RT, Bagshaw SM. Association between implementation of an intensivist-led medical emergency team and mortality. BMJ Qual Saf 2012;21:152-159.

34. Morris DS, Schweickert W, Holena D, et al. Differences in outcomes between ICU attending and senior resident physician led medical emergency team responses. Resuscitation 2012;83:1434-1437.

35. Dukes K, Bunch JL, Chan PS, et al. Assessment of rapid response teams at top-performing hospitals for in-hospital cardiac arrest. JAMA Intern Med 2019;179:1398-1405.

36. Bagshaw SM, Mondor EE, Scouten C, et al. A survey of nurses' beliefs about the medical emergency team system in a Canadian tertiary hospital. Am J Crit Care 2010;19:7483.

37. Butcher BW, Quist CE, Harrison JD, Ranji SR. The effect of a rapid response team on resident perceptions of education and autonomy. J Hosp Med 2015;10:8-12.

38. Health Insurance Review and Assessment Service. Guidance on rapid response system polor project [Internet]. Wonju (KR): Health Insurance Review and Assessment Service, 2019 [cited 2021 Jul 5]. Available from: http://www.hira. or.kr/bbsDummy.do?pgmid=HIRAA020002000100\&brdScnBltNo=4\&brdBltNo=7329.

39. Joint College of Intensive Care Medicine and Australian and New Zealand Intensive Care Society Special Interest Group on Rapid Response Systems; ANZICS Centre for Outcome and Resource Evaluation. Resource use, governance and case load of rapid response teams in Australia and New Zealand in 2014. Crit Care Resusc 2016;18:275282. 